\title{
Impact of 10- and 13-valent pneumococcal conjugate vaccines on incidence of invasive pneumococcal disease in children aged under 16 years in Germany, 2009 to 2012
}

S Weiss (susanne.weiss@med.uni-muenchen.de) ${ }^{1}$, G Falkenhorst ${ }^{2}, \mathbf{M}$ van der Linden ${ }^{3}, \mathbf{M}$ Imöhl${ }^{3}$, R von Kries ${ }^{1}$

1. Ludwig-Maximilians-University of Munich, Institute of Social Paediatrics and Adolescent Medicine, Munich, Germany

2. Robert Koch Institute, Department for Infectious Disease Epidemiology, Berlin, Germany

3. National Reference Centre for Streptococci, Institute of Medical Microbiology, University Hospital RWTH Aachen, Aachen, Germany

Weiss S, Falkenhorst G, van der Linden M, Imöhl M, von Kries R. Impact of 10- and 13-valent pneumococcal conjugate vaccines on incidence of invasive pneumococcal disease in children aged under 16 years in Germany, 2009 to 2012. Euro Surveill. 2015;20(10):pii=21057. Available online: http://www. eurosurveillance.org/ViewArticle.aspx?Articleld=21057

Article submitted on 10 January 2014 / published on 12 March 2015

We assessed the impact of 10-valent and 13-valent pneumococcal vaccines ( $P C V_{10}$ and $\left.P C V_{13}\right)$, which were introduced in Germany in 2009, on the incidence of meningitis and non-meningitis invasive pneumococcal disease (IPD) in children agedunder 16 years in a population previously vaccinated with a sevenvalent vaccine $\left(\mathrm{PCV}_{7}\right)$. Surveillance of IPD (isolation of Streptococcus pneumonia from a normally sterile body site) is based on data from two independent reporting sources: hospitals and laboratories. IPD incidence was estimated by capture-recapture analysis. Incidence rate ratios (IRRs) were calculated for 2009 and 2012, thus comparing pre- and post-PCV10 and PCV13 data. IPD incidence caused by serotypes included in PCV13 decreased in all age and diagnosis groups. A rise in non-vaccine serotype incidence was seen only in children aged under two years. The overall impact varied by age group and infection site: for meningitis IPD in childrenaged under 2, 2-4 and 5-15 years, incidence changed by $3 \%$ (95\% Cl: -31 to 52$),-60 \%$ (95\% Cl: -81 to -17$)$ and $-9 \%$ (95\% Cl: -46 to 53$)$, respectively. A more pronounced incidence reduction was observed for non-meningitis IPD: $-30 \%(95 \% \mathrm{Cl}:-46$ to -7$)$, $-39 \%(95 \% \mathrm{Cl}:-54$ to -20$)$ and $-83 \%(95 \% \mathrm{Cl}:-89$ to -73 ) in childrenaged under 2, 2-4 and 5-15 years, respectively. A higher tropism of the additional serotypes for non-meningitis IPD may be a potential explanation. The heterogeneous findings emphasise the need for rigorous surveillance.

\section{Introduction}

The German Standing Committee on Vaccination (STIKO) included seven-valent pneumococcal conjugate vaccine $\left(\mathrm{PCV}_{7}\right)$ in the infant vaccination calendar for all infants as of July 2006, with a 3+1 schedule given at 2, 3, 4 and 11-14 months of age [1]. Between 2007 and 2009, vaccination with $\mathrm{PCV}_{7}$ prompted a sharp decrease in vaccine serotype incidence for all children aged under 16 years in Germany, whereas nonvaccine serotype incidence rose. Both effects together resulted in a net reduction in IPD incidence [2]. Rising non-PCV7 serotype incidences were also observed in other countries: the most recent and comprehensive meta-analysis of the impact of $\mathrm{PCV}_{7}$ in different populations showed a reduction of about $50 \%$ for the incidence of all IPD and about $60 \%$ for meningitis IPD [3]. After almost complete elimination of $\mathrm{PCV}_{7}$ serotypes in most populations, non-PCV7 serotypes accounted for a substantial proportion of remaining IPD cases, drawing attention to the need for higher-valent vaccines.

In Germany, the switch to higher-valent vaccines took place in April 2009 with the introduction of a 10-valent vaccine ( $\left.P C V_{10}\right)$ (market share in 2010-12: 9\%) and in December 2009, when the 13-valent vaccine (PCV13) was introduced (market share in 2010-2012: 91\%, internal sales figures provided by Pfizer Pharma GmbH). These higher-valent vaccines include all the serotypes in $\mathrm{PCV}_{7}$ and the most frequent non- $\mathrm{PCV}_{7}$ serotypes (PCV10: 1, 5, 7F; PCV13: 1, 3, 5, 6A, 7F and 19A). As $73.6 \%$ of all IPD cases in childrenaged under 16 years in Germany from 2007 to 2009 were caused by PCV13 serotypes [2] and given that the effectiveness of the six additional serotypes in $\mathrm{PCV}_{13}$ has been established using the Broome method [4], a considerable benefit from the switch to higher-valent pneumococcal vaccines was expected.

In Germany, sustained surveillance for IPD is based on two independent data sources: active surveillance in hospitals and passive sentinel surveillance through microbiological laboratories. The hospitals and laboratories report on a voluntary basis, and there is an option for laboratories to send all pneumococcal isolates from IPD cases for serotyping to the National Reference Center for Streptococci in Aachen free of 
charge. Case ascertainment from these two independent sources allows underreporting to be corrected for by capture-recapture analysis.

Since vaccination coverage of pneumococcal conjugate vaccines has been above $85 \%$ since 2007 , as estimated by internal sales figures provided by Pfizer Pharma $\mathrm{GmbH}$, our data provide a basis to assess the impact of higher-valent vaccination ( $\mathrm{PCV}_{10}$ and $\left.\mathrm{PCV}_{13}\right)$ up to three years after its introduction (2009 to 2012). Due to the limited market share of PCV 10 ( $(10 \%)$, we focused our research on the overall impact of both vaccines: $P C V_{10}$ and $P C_{1}$ 13. The aim of our study was to assess whether the incidence in $\mathrm{PCV}_{13}$ serotypes decreased during this period and whether there was a similar decrease in overall (PCV13 and non-PCV13 serotype) IPD incidence.

\section{Methods}

\section{Data sources}

Hospital surveillance of IPD in children aged under 16 years comprises all paediatric hospitals as well as paediatric hospital wards in Germany ( $n>400$, response rate $>95 \%$ ) [5]. It is managed by the German paediatric surveillance unit, Erhebungseinheit für seltene pädiatrische Erkrankungen (ESPED). In the laboratory sentinel surveillance, cases are reported through a web interface (PneumoWeb) hosted by the Robert Koch Institute [2,6-8].

\section{Case definition}

Cases are children under 16 years of age treated for IPD as inpatients in a paediatric hospital or paediatric ward in general hospitals in Germany. IPD was defined as Streptococcus pneumoniae being isolated from at least one culture of blood, cerebrospinal fluid or a sample from any other normally sterile body site. Isolates from middle ear fluid were not included. Both surveillance sources (hospitals and laboratories) applied the same case definition.

\section{Definition of serotype coverage}

Serotypes were grouped into vaccine type (VT) serotypes, namely $\mathrm{PCV}_{7}$ serotypes (4, 6B, 9V, 14, 18C, 19F, $23 \mathrm{~F}$ ) plus the additional serotypes included in $\mathrm{PCV}_{13}$ $(1,3,5,6 \mathrm{~A}, 7 \mathrm{~F}, 19 \mathrm{~A})$ and into non-vaccine type (NVT) serotypes including all other serotypes. For cases for which serotype data were not available - because isolates were not sent for serotyping - the same serotype distribution as for the serotyped cases was assumed.

Pneumococcal isolates were serotyped at the German National Reference Center for Streptococci, by Neufeld's Quellung reaction using type and factor sera provided by the Statens Serum Institut, Copenhagen, Denmark.

\section{Statistical analysis}

Capture-recapture calculation (CRC) allows for adjustment of incomplete reporting in (at least) two sources by identifying overlapping cases and applying Bayes' probability theory to estimate the number of cases not included in either of the sources [9]. To avoid bias caused by small sample sizes, the Chapman estimator [10] was applied.

For the analysis of children too young to be vaccinated, we defined these as all children aged $\leq 2$ months. Although children may already receive the first dose when two months-old, we aimed to take account of the tendency of belated vaccination in Germany [11] as well as of inaccuracy in the exact age of the children: Due to data protection, the day of birth was not provided in our study and it was therefore assumed that all children were born on the first day of the month.

In this age subgroup $\leq 2$ months, CRC was not possible since in 2012, all cases from the laboratory surveillance were included in the hospital surveillance, which renders CRC impossible. Therefore the analysis of the age group $\leq 2$ months, and the comparison with children aged 3-23 months, was based on the cumulative number of cases in either source (ESPED and PneumoWeb).

The population denominator to convert the IPD case number estimates into incidence rates (per 100,000 children) was based on age-specific (0-2, 2-4, 5-15 and $0-15$ years) population figures provided by the German Federal Statistical Office [12]. To assess the impact of the higher-valent pneumococcal conjugate vaccines ( $P \mathrm{CV}_{10}$ and $P \mathrm{CV}_{13}$ ), we calculated incidence rate ratios (IRRs): we compared the incidence during years when $\mathrm{PCV}_{10}$ and $\mathrm{PCV}_{13}$ were exclusively used (2010, 2011 and 2012) with that in 2009, the last year of $\mathrm{PCV}_{7}$ use in Germany. A rate ratio of 1 indicates no effect of the switch from $\mathrm{PCV}_{7}$ to $\mathrm{PCV}_{10}$ and $\mathrm{PCV}_{13}$. Rate ratiosless than 1 show a declining incidence of $I P D$, rate ratios greater than 1 indicate rising incidence. The $95 \%$ confidence intervals for the IRRs were calculated using the method described by Armitage and Berry [13]. To compensate for chance fluctuations of the incidences in 2009 and 2012, we additionally calculated the mean values of the two last years of $\mathrm{PCV}_{7}$ vaccination (2008-09) as reference for the IRR calculation and compared them with the mean values of the last two years of $\mathrm{PCV}_{13}$ vaccination (2011-12).

All analyses were performed separately for meningitis and non-meningitis IPD cases, using SAS 9.2 software.

\section{Results}

Impact on vaccine-type incidence of invasive pneumococcal disease

From 2009 to 2012, there was a decrease in the incidence of IPD caused by serotypes included in PCV13 in all age groups for non-meningitis IPD, whereas a decrease for meningitis IPD could be observed in one age group (2-4 years) only. The absolute change in incidence was five- to 10 -fold higher for non-meningitis IPD than meningitis IPD. The relative decrease ranged between $33 \%$ and $91 \%$, depending on age and clinical 


\section{TABLE 1}

Incidence and incidence changes of meningitis and non-meningitis invasive pneumococcal disease in children aged under 16 years caused by serotypes in the 13-valent pneumococcal conjugate vaccine, based on capture-recapture calculation ${ }^{\mathrm{a}}$, Germany, 2009 and 2012

\begin{tabular}{|c|c|c|c|c|c|}
\hline \multirow[b]{2}{*}{ Age in years } & \multirow[b]{2}{*}{ Diagnosis } & \multicolumn{4}{|c|}{ Vaccine type serotype incidence or change per 100,000 children } \\
\hline & & $\begin{array}{c}\text { Incidence }(95 \% \mathrm{Cl}) \\
2009\end{array}$ & $\begin{array}{c}\text { Incidence }(95 \% \mathrm{Cl}) \\
2012\end{array}$ & $\begin{array}{c}\text { Absolute } \\
\text { incidence change } \\
\text { (95\% Cl) } \\
2009 \text { vs } 2012\end{array}$ & $\begin{array}{c}\text { Relative } \\
\text { incidence change } \\
\%(95 \% \mathrm{Cl}) \\
2009 \text { vS } 2012\end{array}$ \\
\hline \multirow{2}{*}{$<2$} & Meningitis & $2.2(1.3$ to 3.1$)$ & $1.5(1.0$ to 1.9$)$ & $-0.7(-1.8$ to 0.3$)$ & $-33(-62$ to 18$)$ \\
\hline & Non-meningitis & $7.3(4.6$ to 10.1$)$ & $1.1(0.6$ to 1.7$)$ & $-6.2(-7.9$ to -4.7$)$ & $-85(-91$ to -74$)$ \\
\hline \multirow{2}{*}{$2-4$} & Meningitis & $0.5(0.3$ to 0.7$)$ & $0.1(0.05$ to 0.07$)$ & $-0.5(-0.9$ to -0.2$)$ & $-91(-99$ to -30$)$ \\
\hline & Non-meningitis & $4.7(2.8$ to 6.7$)$ & 2.0 (0.6 to 3.3$)$ & $-2.8(-4.0$ to -1.7$)$ & $-58(-71$ to -40$)$ \\
\hline \multirow{2}{*}{$5-15$} & Meningitis & $0.1(0.1$ to 0.2$)$ & $0.07(0.05$ to 0.10$)$ & $-0.1(-0.18$ to 0.04$)$ & $-50(-81$ to 36$)$ \\
\hline & Non-meningitis & $1.3(0.5$ to 2.0$)$ & $0.2(0.1$ to 0.3$)$ & $-1.1(-1.3$ to -0.8$)$ & $-84(-90$ to -73$)$ \\
\hline \multirow{2}{*}{ All $<16$} & Meningitis & $0.4(0.3$ to 0.6$)$ & $0.2(0.2$ to 0.3$)$ & $-0.2(-0.4$ to -0.1$)$ & $-49(-69$ to -20$)$ \\
\hline & Non-meningitis & 2.6 (1.9 to 3.3$)$ & 0.7 (0.4 to 0.9$)$ & $-2.0(-2.3$ to -1.6$)$ & $-75(-80$ to -68$)$ \\
\hline
\end{tabular}

$\mathrm{Cl}$ : confidence interval; ESPED: German paediatric surveillance unit; IRR: incidence rate ratio; PneumoWeb: web interface for reporting of cases through laboratory sentinel surveillance.

Two-digits after the decimal point were used when necessary to avoid figures being rounded to o.

Figures in bold indicate a statistically significant decrease or increase, since the $95 \% \mathrm{Cl}$ does not include o.

a Capture-recapture calculation was based on 231 vaccine-type invasive pneumococcal disease cases observed in two sources (without matches) - hospital (ESPED) and laboratory (PneumoWeb) surveillance - for 2009 and 2012 combined. For cases for whom serotype data were not available, the same serotype distribution as for the serotyped cases was assumed. The serotyping rate was $75 \%$.

b Calculated as 1 - IRR, as a percentage.

\section{TABLE 2}

Incidence and incidence changes of meningitis and non-meningitis invasive pneumococcal disease in children aged under 16 years caused by serotypes not included in the 13-valent pneumococcal conjugate vaccine, based on capture-recapture calculationa, Germany, 2009 and 2012

\begin{tabular}{|c|c|c|c|c|c|}
\hline \multirow[b]{2}{*}{ Age in years } & \multirow[b]{2}{*}{ Diagnosis } & \multicolumn{4}{|c|}{ Non-vaccine type serotype incidence or change per 100,000 children } \\
\hline & & $\begin{array}{c}\text { Incidence }(95 \% \mathrm{Cl}) \\
2009\end{array}$ & $\begin{array}{c}\text { Incidence }(95 \% \mathrm{Cl}) \\
2012\end{array}$ & $\begin{array}{c}\text { Absolute } \\
\text { incidence change } \\
(95 \% \mathrm{Cl}) \\
2009 \text { VS } 2012\end{array}$ & $\begin{array}{c}\text { Relative } \\
\text { incidence change } \\
\%(95 \% \mathrm{Cl}) \\
2009 \text { vS } 2012\end{array}$ \\
\hline \multirow{2}{*}{$<2$} & Meningitis & $1.4(0.9$ to 2.0$)$ & $2.3(1.5$ to 3.0$)$ & $0.8(-0.2$ to 1.9$)$ & $59(-10$ to 82$)$ \\
\hline & Non-meningitis & $1.6(1.0$ to 2.2$)$ & $5.2(2.6$ to 7.8$)$ & $3.6(2.2$ to 5.1$)$ & $225(101$ to 428$)$ \\
\hline \multirow{2}{*}{$2-4$} & Meningitis & $0.7(0.4$ to 1.0$)$ & $0.4(0.3$ to 0.5$)$ & $-0.3(-0.8$ to 0.2$)$ & $-39(-74$ to 42$)$ \\
\hline & Non-meningitis & $1.8(1.1$ to 2.5$)$ & $2.0(0.6$ to 3.3$)$ & $0.2(-0.1$ to 0.7$)$ & $11(-73$ to 29$)$ \\
\hline \multirow{2}{*}{$5-15$} & Meningitis & $0.2(0.1$ to 0.3$)$ & $0.3(0.2$ to 0.4$)$ & $0.04(-0.1$ to 0.2$)$ & $17(-18$ to 37$)$ \\
\hline & Non-meningitis & $0.4(0.2$ to 0.7$)$ & 0.09 (0.04 to 0.13$)$ & $-0.4(-0.5$ to -0.2$)$ & $-79(-91$ to -54$)$ \\
\hline \multirow{2}{*}{ All $<16$} & Meningitis & $0.5(0.3$ to 0.6$)$ & $0.5(0.4$ to 0.6$)$ & $0.1(-0.1$ to 0.3$)$ & $14(-21$ to 65$)$ \\
\hline & Non-meningitis & 0.8 (o.6 to 1.0$)$ & $1.0(0.6$ to 1.5$)$ & $0.3(0.01$ to 0.5$)$ & $33(2$ to 74$)$ \\
\hline
\end{tabular}

$\mathrm{Cl}$ : confidence interval; ESPED: German paediatric surveillance unit; IRR: incidence rate ratio; PneumoWeb: web interface for reporting of cases through laboratory sentinel surveillance.

Two-digits after the decimal point were used when necessary to avoid figures being rounded to 0.

Figures in bold indicate a statistically significant decrease or increase, since the $95 \% \mathrm{Cl}$ does not include 0 .

a Capture-recapture calculation was based on 181 non-vaccine-type invasive pneumococcal disease cases observed in two sources (without matches) - hospital (ESPED) and laboratory (PneumoWeb) surveillance - for 2009 and 2012 combined. For cases for whom serotype data were not available, the same serotype distribution as for the serotyped cases was assumed. The serotyping rate was $75 \%$.

b Calculated as 1 - IRR, as a percentage. 


\section{TABLE 3}

Meningitis invasive pneumococcal disease in children aged under 16 years: reported cases, incidence estimates and rate ratios, Germany, 2009-12

\begin{tabular}{|c|c|c|c|c|c|}
\hline \multirow{2}{*}{ Value } & \multirow{2}{*}{$\begin{array}{l}\text { Age group } \\
\text { in years }\end{array}$} & \multirow{2}{*}{\begin{tabular}{|c|}
$\begin{array}{c}\text { Last year of } \mathrm{PCV} 7 \\
\text { vaccination period }\end{array}$ \\
2009 \\
\end{tabular}} & \multicolumn{3}{|c|}{$P C V_{10}$ and $P C_{13}$ vaccination period } \\
\hline & & & 2010 & 2011 & 2012 \\
\hline \multirow{4}{*}{$\begin{array}{l}\text { Number of reported cases in } \\
\text { the two surveillance sources: } \\
\text { ESPED; Pneumoweb }\end{array}$} & $<2$ & $24 ; 15$ & 30; 21 & $21 ; 11$ & 29; 16 \\
\hline & $2-4$ & $15 ; 7$ & $16 ; 10$ & $8 ; 7$ & $8 ; 5$ \\
\hline & $5-15$ & $21 ; 9$ & $9 ; 4$ & $12 ; 10$ & $14 ; 12$ \\
\hline & All $<16$ & $60 ; 31$ & $55 ; 35$ & $41 ; 28$ & $51 ; 33$ \\
\hline \multirow{4}{*}{$\begin{array}{l}\text { Estimated number of cases } \\
\text { by CRC }(95 \% \mathrm{Cl})\end{array}$} & $<2$ & $49.0(30.0$ to 68.0$)$ & $55.8(39.5$ to 72.1$)$ & $51.8(23.4$ to 80.2$)$ & $50.0(34.2$ to 65.8$)$ \\
\hline & $2-4$ & $24.6(14.2$ to 35.0$)$ & $30.2(17.6$ to 42.7$)$ & $23.0(7.8$ to 38.2$)$ & 9.8 (7.4 to 12.2$)$ \\
\hline & $5-15$ & $30.4(20.6$ to 40.3$)$ & $24.0(4.4$ to 43.6$)$ & $22.8(14.1$ to 31.6$)$ & $26.9(17.3$ to 36.4$)$ \\
\hline & All<16 & $104.0(80.2$ to 127.9$)$ & $110.0(81.6$ to 138.4$)$ & $97.6(64.3$ to 131.0$)$ & $86.7(68.0$ to 105.3$)$ \\
\hline \multirow{4}{*}{$\begin{array}{l}\text { Estimated incidence by CRC } \\
\text { per } 100,000 \text { children }(95 \% \mathrm{Cl})\end{array}$} & $<2$ & $3.6(2.2$ to 5.0$)$ & $4.1(2.9$ to 5.3$)$ & $3.8(1.7$ to 5.9$)$ & $3.7(2.4$ to 4.5$)$ \\
\hline & $2-4$ & $1.2(0.7$ to 1.7$)$ & $1.5(0.9$ to 2.1$)$ & $1.1(0.4$ to 1.9$)$ & $0.5(0.4$ to 0.6$)$ \\
\hline & $5-15$ & $0.4(0.2$ to 0.5$)$ & $0.3(0.1$ to 0.5$)$ & $0.3(0.2$ to 0.4$)$ & $0.3(0.2$ to 0.4$)$ \\
\hline & All $<16$ & 0.9 (0.7 to 1.1$)$ & 0.9 (0.7 to 1.2$)$ & 0.8 (o.6 to 1.1 ) & 0.7 ( 0.6 to 0.9 ) \\
\hline \multirow{4}{*}{$\operatorname{IRR}^{\mathrm{a}}(95 \% \mathrm{Cl})$} & $<2$ & \multirow{4}{*}{$\begin{array}{c}\text { NA } \\
\text { Year of reference }\end{array}$} & 1.14 (0.78 to 1.68$)$ & $1.06(0.72$ to 1.57$)$ & 1.03 (0.69 to 1.52 ) \\
\hline & $2-4$ & & 1.22 (0.72 to 2.09$)$ & $0.93(0.53$ to 1.65$)$ & 0.40 (0.19 to 0.83$)$ \\
\hline & $5-15$ & & $0.80(0.47$ to 1.36$)$ & 0.77 (0.44 to 1.32$)$ & 0.91 (0.54 to 1.53) \\
\hline & All<16 & & 1.06 (0.82 to 1.39$)$ & $0.95(0.72$ to 1.26$)$ & 0.85 (0.64 to 1.13$)$ \\
\hline
\end{tabular}

$\mathrm{Cl}$ : confidence interval; CRC: capture-recapture calculation; ESPED: German paediatric surveillance unit; IRR: incidence rate ratio; NA: not applicable; PCV: pneumococcal conjugate vaccine; PneumoWeb: web interface for reporting of cases through laboratory sentinel surveillance.

a With reference to the incidence rate in 2009. IRRs with 95\% Cls excluding 1 are shown in bold.

\section{TABLE 4}

Non-meningitis invasive pneumococcal disease in children aged under 16 years: reported cases, incidence estimates and rate ratios, Germany, 2009-12

\begin{tabular}{|c|c|c|c|c|c|}
\hline \multirow{2}{*}{ Value } & \multirow{2}{*}{$\begin{array}{l}\text { Age group } \\
\text { in years }\end{array}$} & \multirow{2}{*}{$\begin{array}{c}\text { Last year of PCV7 } \\
\text { vaccination period } \\
2009\end{array}$} & \multicolumn{3}{|c|}{$P C V_{10}$ and $P C_{13}$ vaccination period } \\
\hline & & & 2010 & 2011 & 2012 \\
\hline \multirow{4}{*}{$\begin{array}{l}\text { Number of reported } \\
\text { cases in the two } \\
\text { surveillance sources: } \\
\text { ESPED; Pneumoweb }\end{array}$} & $<2$ & $42 ; 33$ & $35 ; 31$ & $21 ; 16$ & $24 ; 23$ \\
\hline & $2-4$ & 47; 30 & $22 ; 19$ & $27 ; 16$ & $21 ; 14$ \\
\hline & $5-15$ & $32 ; 25$ & $23 ; 28$ & $21 ; 29$ & $10 ; 8$ \\
\hline & All $<16$ & $121 ; 88$ & $80 ; 78$ & $69 ; 61$ & $55 ; 45$ \\
\hline \multirow{4}{*}{$\begin{array}{l}\text { Estimated number of } \\
\text { cases by CRC }(95 \% \mathrm{CI})\end{array}$} & $<2$ & $120.8(75.6$ to 166.1$)$ & $127.0(68.8$ to 185.2$)$ & $61.3(29.7$ to 93.0$)$ & $84.7(42.3$ to 127.1$)$ \\
\hline & $2-4$ & $134.3(80.3$ to 188.2$)$ & $75.7(34.8$ to 116.5$)$ & $67.0(35.7$ to 98.3$)$ & $81.5(25.5$ to 137.5$)$ \\
\hline & $5-15$ & $142.0(58.0$ to 226.0$)$ & $115.0(48.7$ to 181.3$)$ & 109.0 (46.8 to 171.2$)$ & 23.8 (10.9 to 36.6$)$ \\
\hline & All<16 & $397.1(287.5$ to 506.8$)$ & $317.7(220.4$ to 414.9$)$ & $237.3(160.9$ to 313.8$)$ & $190.0(118.5$ to 261.4$)$ \\
\hline \multirow{4}{*}{$\begin{array}{l}\text { Estimated incidence by } \\
\text { CRC per } 100,000 \text { children } \\
(95 \% \mathrm{Cl})\end{array}$} & $<2$ & $8.9(5.6$ to 12.3$)$ & $9.4(5.1$ to 13.7$)$ & $4.6(2.2$ to 6.9$)$ & $6.3(3.1$ to 9.4$)$ \\
\hline & $2-4$ & $6.5(3.9$ to 9.2$)$ & $3.7(1.7$ to 5.7$)$ & $3.3(1.7$ to 4.8$)$ & $4.0(1.2$ to 6.4$)$ \\
\hline & $5-15$ & $1.7(0.7$ to 2.7$)$ & 1.4 (0.6 to 2.2$)$ & 1.3 (o.6 to 2.1 ) & $0.3(0.1$ to 0.4$)$ \\
\hline & All<16 & $3.4(2.4$ to 4.3$)$ & $2.7(1.9$ to 3.5$)$ & 2.0 (1.4 to 2.7$)$ & $1.6(1.0$ to 2.3$)$ \\
\hline \multirow{4}{*}{$\operatorname{IRR}^{\mathrm{a}}(95 \% \mathrm{Cl})$} & $\ll 2$ & \multirow{4}{*}{$\begin{array}{c}\text { NA } \\
\text { Year of reference }\end{array}$} & $1.05(0.82$ to 1.35$)$ & $0.51(0.37$ to 0.69$)$ & $0.70(0.53$ to 0.93$)$ \\
\hline & $2-4$ & & $0.56(0.42$ to 0.75$)$ & $0.50(0.37$ to 0.67$)$ & $0.61(0.46$ to 0.80$)$ \\
\hline & $5-15$ & & 0.82 (0.64 to 1.05$)$ & 0.78 (o.61 to 1.01$)$ & $0.17(0.11$ to 0.27$)$ \\
\hline & All $<16$ & & $0.81(0.70$ to 0.93$)$ & $0.61(0.52$ to 0.71$)$ & $0.50(0.42$ to 0.60$)$ \\
\hline
\end{tabular}

$\mathrm{Cl}$ : confidence interval; CRC: capture-recapture calculation; ESPED: German paediatric surveillance unit; IRR: incidence rate ratio; NA: not applicable; PCV: pneumococcal conjugate vaccine; PneumoWeb: web interface for reporting of cases through laboratory sentinel surveillance.

a With reference to the incidence rate in 2009. IRRs with $95 \%$ CIs excluding 1 are shown in bold. 


\section{TABLE 5}

Sensitivity analysis: incidence rate ratios of meningitis and non-meningitis invasive pneumococcal disease in children aged under 16 years (mean of 2011-12 vs mean of 2008-09), based on capture-recapture calculation ${ }^{\mathrm{a}}$, Germany

\begin{tabular}{|c|c|c|}
\hline \multirow{2}{*}{$\begin{array}{l}\text { Age group } \\
\text { in years }\end{array}$} & \multicolumn{2}{|c|}{$\begin{array}{c}\text { IRR: average of } 2011-12 \\
\text { vs average of } 2008-09(95 \% \mathrm{Cl})\end{array}$} \\
\hline & Meningitis IPD & Non-meningitis IPD \\
\hline$<2$ & 1.06 (0.80 to 1.40$)$ & $0.58(0.47$ to 0.71$)$ \\
\hline $2-4$ & $0.56(0.36$ to 0.87$)$ & 0.76 (0.61 to 0.94$)$ \\
\hline 5-15 & 1.16 (0.77 to 1.72 ) & 0.53 (0.43 to 0.65$)$ \\
\hline All $<16$ & 0.95 (0.78 to 1.16) & $0.65(0.58$ to 0.73$)$ \\
\hline
\end{tabular}

$\mathrm{Cl}$ : confidence interval; ESPED: German paediatric surveillance unit; IPD: invasive pneumococcal disease; IRR: incidence rate ratio; PneumoWeb: web interface for reporting of cases through laboratory sentinel surveillance.

$95 \% \mathrm{Cls}$ not including 1 are shown in bold.

a Capture-recapture calculation was based on 798 IPD cases observed in two sources (without matches) - hospital (ESPED) and laboratory (PneumoWeb) surveillance - for 2008, 2009, 2011 and 2012 combined.

presentation. The relative incidence decrease was lowest (and not statistically significant) for meningitis IPD in the youngest age group, i.e. under two years (Table 1).

In the under two years age group, a distinction needs to be made between children too young to be vaccinated ( $\leq 2$ months) and those for whom the universal vaccination recommendation applies (3-23 months). In 2009, VT meningitis IPD cases aged $\leq 2$ months accounted for 5 of 19 VT cases in children aged under two years compared with 9 of 14 cases in 2012. Among the nine 2012 cases, five were due to serotype $7 \mathrm{~F}$. The high proportion of $7 \mathrm{~F}$ among these cases contrasts with the vaccine serotype distribution in all older age groups ( $>2$ months), among whom serotype $7 \mathrm{~F}$ had almost vanished (one case in the age group 3-23 months, one among children aged 2-15 years). The age group $\leq 2$ months was the only group in which VT meningitis IPD increased. In children aged 3-23 months, the number of meningitis cases with $\mathrm{PCV}_{13}$ serotypes decreased from 14 cases in 2009 to five in 2012.

Regarding non-meningitis IPD cases, in children aged $\leq 2$ months, the number of VT IPD cases decreased from six (2009) to three (2012); in children aged 3-23 months, the number of VT IPD cases fell from 47 to five.

\section{Impact on non-vaccine-type invasive}

pneumococcal disease incidence

For non-PCV13 vaccine serotypes, an inconsistent pattern was observed. There was an increase in the incidence of NVT serotypes in childrenaged under two years (for children $\leq 2$ months as well as for those aged 3-23 months), which was statistically significant for non-meningitis IPD but not for meningitis IPD. In older age groups, the incidence of NVT IPD increased in some age groups while decreasing in others. There was a statistically significant decrease of non-meningitis IPD in 5-15 year-old children (Table 2).

Impact on overall (vaccine type and nonvaccine type) incidence of meningitis and nonmeningitis invasive pneumococcal disease The impact of PCV13 on the overall number and incidence of meningitis IPD cases is shown in Table 3. While barely no change or even a slight rise in the number of meningitis IPD cases is shown in the laboratory source PneumoWeb, the hospital data source showed a decrease in the number of these cases among children aged two years or older, but also no decrease in those aged under two years. This was confirmed in the capture-recapture analysis: some decrease in older age groups (two years and above) and virtually no incidence reduction in children aged under two years. The IRRs suggest an incidence reduction, which was significant for the 2-4 years age group only: $-60 \%(95 \%$ $\mathrm{Cl}:-81$ to -17$)$. For children aged 5-15 years, CRC incidence changed by $-9 \%$ ( $95 \% \mathrm{Cl}:-46$ to 53$)$. For children aged under two years, the change was $3 \%(95 \% \mathrm{Cl}:-31$ to 52).

In order to disentangle the changes in children too young to be vaccinated ( $\leq 2$ months) and those for whom the universal vaccination recommendation applies (3-23 months), we report data for each subgroup: for children $\leq 2$ months, the incidence of meningitis IPD

\section{TABLE 6}

Absolute number and percentage of vaccine type serotypes $^{\mathrm{a}}$ in paediatric $(<16$ years) invasive pneumococcal disease cases by diagnosis (meningitis and non-meningitis), Germany, 2009

\begin{tabular}{|l|c|c|c|c|}
\hline \multirow{2}{*}{$\begin{array}{l}\text { Age } \\
\text { group } \\
\text { in years }\end{array}$} & $\begin{array}{c}\text { VT meningitis IPD } \\
\text { Number of } \\
\text { cases }^{\mathrm{b}}\end{array}$ & $\begin{array}{c}\text { Percentage } \\
\text { of meningitis } \\
\text { IPD cases by } \\
\text { any serotype } \\
\text { (95\% CI) }\end{array}$ & $\begin{array}{c}\text { Number } \\
\text { of } \\
\text { cases }^{\mathrm{b}}\end{array}$ & $\begin{array}{c}\text { Percentage of } \\
\text { non-meningitis } \\
\text { IPD cases by } \\
\text { any serotype } \\
\text { (95\% CI) }\end{array}$ \\
\hline$<2$ & 30 & $61(48$ to 75$)$ & 99 & $82(74$ to 90$)$ \\
\hline $2-4$ & 11 & $43(28$ to 64$)$ & 98 & $73(64$ to 82$)$ \\
\hline $5-15$ & 12 & $44(26$ to 58$)$ & 107 & $75(65$ to 85$)$ \\
\hline All<16 & 53 & $49(40$ to 59$)$ & 304 & $77(72$ to 82$)$ \\
\hline
\end{tabular}

$\mathrm{Cl}$ : confidence interval; ESPED: German paediatric surveillance unit; IPD: invasive pneumococcal disease; PneumoWeb: web interface for reporting of cases through laboratory sentinel surveillance; VT: vaccine type.

VT serotypes were all serotypes included in the 13-valent pneumococcal vaccine (PCV13), i.e. seven-valent pneumococcal vaccine $\left(\mathrm{PCV}_{7}\right)$ serotypes $(4,6 \mathrm{~B}, 9 \mathrm{~V}, 14,18 \mathrm{C}, 19 \mathrm{~F}, 23 \mathrm{~F})$ plus an additional six serotypes $(1,3,5,6 \mathrm{~A}, 7 \mathrm{~F}, 19 \mathrm{~A})$.

b Numbers according to capture-recapture calculation based on 257 invasive pneumococcal disease cases observed in two sources (without matches) - hospital (ESPED) and laboratory (PneumoWeb) surveillance - for 2009. For cases for whom serotype data were not available, the same serotype distribution as for the serotyped cases was assumed. The serotyping rate was $75 \%$. 
increased from 1.1 per 100,000 children in 2009 to 1.5 per 100,000 in 2012. In children aged 3-23 months, it was 2.1/100,000 in 2009 and 2.2/100,000 in 2012.

A different pattern was observed for non-meningitis IPD cases (Table 4 ). The numbers in each data source showed a decrease from 2009 to 2012 (with some fluctuations in 2010 and 2011). This decrease was confirmed in the capture-recapture analysis: a statistically significant reduction in incidence of non-meningitis IPD was observed in all age groups, except for children $\leq 2$ months, in whom incidence was $1.4 / 100,000$ in both 2009 and 2012. For children aged under 2 years, the decrease was $-30 \%(95 \% \mathrm{Cl}:-46$ to -7$)$. For older children aged 2-4 and 5-15 years, the decrease was $-39 \%$ (95\% Cl: -54 to -20$)$ and $-83 \%$ (95\% Cl: -89 to -73), respectively.

In order to confirm that the observed results did not reflect an artefact resulting from the use of CRC, we also assessed the changes in case numbers and incidence rates between 2009 and 2012 solely based on the observed number of cases reported in both surveillance sources (counting cases observed in both sources only once): the changes (IRRs) related to the introduction of $\mathrm{PCV}_{10}$ and $\mathrm{PCV}_{13}$ were almost identical to those based on CRCs.

We also calculated CRC-based IRRs for the two-year periods 2008-09 and 2011-12 (Table 5), which yielded very similar results to our comparison of 2012 with 2009. Only the decrease of non-meningitis IPD in 5-15 year-old children $(1-$ IRR $=-46 \%(95 \% \mathrm{CI}:-57$ to -35$)$ was outside the $95 \% \mathrm{Cls}$ of the corresponding result in Table 4 ( 1 - IRR: $-83 \%$ (95\% Cl: -89 to -73 ) and thus significantly and substantially smaller in the analysis which compared 2008-09 to 2011-12, reflecting the sharp decrease in incidence in this age group in 2012.

The percentages of VT serotypes in IPD cases among children aged under 16 years in 2009 is shown in Table 6. This percentage was smaller for meningitis IPD than for non-meningitis IPD in all age groups. The VT serotypes in 2009 consisted mainly $(84 \%, 300 / 357)$ of the six serotypes $(1,3,5,6 \mathrm{~A}, 7 \mathrm{~F}, 19 \mathrm{~A})$ that were not contained in $\mathrm{PCV}_{7}$.

\section{Discussion}

For non-meningitis IPD, the introduction of PCV10 and PCV13 prompted a marked decrease in the incidence of IPD cases caused by PCV13 serotypes. This was not confined to the PCV13-vaccinated cohorts aged under two years but was almost as pronounced in those older than two years. An increasing incidence of IPD cases caused by NVT serotypes was solely observed in children under two years-old. This NVT increase, however, was smaller than the VT decrease, so that an overall decrease of non-meningitis IPD (regardless of serotype) was observed in all age groups.
In contrast, for meningitis IPD, we did not observe a decrease in the VT incidence in children aged under two years, nor in the oldest age group (5-15 years). Therefore, the overall incidence decrease (regardless of serotype) was limited to 2-4 year-old children.

The clear decrease of $\mathrm{PCV}_{13}$ serotypes in non-meningitis IPD in children under two years-old reflects the high effectiveness of $P_{C} V_{13}$ against the six additional serotypes $(1,3,5,6 \mathrm{~A}, 7 \mathrm{~F}$ and $19 \mathrm{~A})$ not contained in $\mathrm{PCV}_{7}$, as demonstrated by Miller et al. [4]. The additional effect in older age groups not vaccinated with $\mathrm{PCV}_{10}$ or $\mathrm{PCV}_{13}$ indicates herd protection.

In accordance with the previously reported increase in non-PCV 7 serotypes after the introduction of $\mathrm{PCV}_{7}$ [3], we observed an increase of non-PCV13 serotypes three years after the introduction of $\mathrm{PCV}_{13}$. In our data, this early increase was confined to the vaccinated cohorts aged under two years, where it was substantial in nonmeningitis IPD, but did not reach statistical significance in meningitis IPD. From a clinical and public health perspective, the overall net impact on IPD incidence (regardless of VT or NVT serotype) is most relevant. While there was an overall decrease of non-meningitis IPD incidence in all age groups, the decrease of meningitis IPD incidence was confined to children in the age group 2-4 years. At first glance, this differential impact is surprising. A likely explanation is the lower proportion of PCV13 serotypes among meningitis IPD cases ( $49 \% ; 95 \% \mathrm{Cl}: 40$ to 59 ) than among non-meningitis IPD cases (77\%; 95\% Cl: 72 to 82) in 2009 when PCV13 was introduced in Germany, meaning that a larger proportion of non-meningitis IPD was preventable by PCV13. The clear decrease in the non-meningitis IPD incidence (regardless of serotype) might theoretically be due to less frequent blood culturing. However, previous findings rather suggested increasing blood culturing rates since the introduction of infant pneumococcal vaccination in Germany [2].

Although chance might be another explanation, given the wide $95 \% \mathrm{Cls}$ of the IRRs, biological explanations related to the tropism of different pneumococcal serotypes appear more likely: German data collected in 1997-98 (during the pre-vaccination period) showed an about equal incidence of meningitis and non-meningitis IPD for serotypes $6 \mathrm{~A}, 7 \mathrm{~F}$ and $19 \mathrm{~A}$, whereas the incidence of serotypes 1,3 and 5 was significantly higher in non-meningitis than in meningitis IPD [6]. A similar pattern was observed after the introduction of PCV in 2007 (data not shown). A literature review published in 2013, with observations from other countries, addressed the issue of tropism of different pneumococcal serotypes: serotypes $1,19 \mathrm{~A}$ and 3 were identified as predominant for pneumococcal pneumonia but not for meningitis IPD during the post- $\mathrm{PCV}_{7}$ period [14]. $A$ recent paper from India, not included in the review, reported that serotypes 1,5 and $7 F$ (three of the six additional serotypes in $\left.\mathrm{P} \mathrm{V}_{13}\right)$ caused more pneumonia than meningitis [15]. 
For children aged under two years, the decreased incidence of meningitis IPD was not only less than that of non-meningitis IPD in this age group, but no decrease was observed at all. One explanation might be an increase in the number of cases caused by NVT serotypes. However, this increase was not statistically significant. Notable was an increase in the number of cases caused by VT serotypes in children $\leq 2$ monthsold, in particular serotype $7 \mathrm{~F}$. Children $\leq 2$ months of age are too young to be vaccinated, according to the German vaccination schedule, and can thus only indirectly benefit from vaccination through herd protection. The reason for the absence of herd protection in this age group in 2012 is unclear.

There are limited data on the impact of $\mathrm{PCV}_{13}$ on the incidence of IPD in previously PCV7-vaccinated populations and distinctions between non-meningitis and meningitis IPD are only made in one study: for England and Wales, where $\mathrm{PCV}_{13}$ replaced $\mathrm{PCV}_{7}$ in April 2010, Miller et al. reported a $50 \%$ reduction in the number of cases caused by $\mathrm{PCV}_{13}$ serotypes (for meningitis and non-meningitis IPD combined) in childrenaged undertwo years after one year of $\mathrm{PCV}_{13}$ use [4]. In a multicentre study from eight hospitals in the United States (where PCV13 was used as of March 2010), IPD cases per total admissions were analysed, comparing the mean of 2007-09 with the number of cases in 2011. A $57 \%$ decrease in $\mathrm{PCV}_{13}$ serotypes and a $42 \%$ reduction in IPD cases per total admissions for children aged underfive years was reported. Meningitis cases were reduced the least [16]. Data from Denmark, where PCV13 was introduced in April 2010, show a decrease of IPD incidence (regardless of clinical entity) by about a third in children under two years-old [17].

A strength of our study is the separate analysis of meningitis and non-meningitis IPD cases. Differences in incidence of meningitis and non-meningitis IPD show the importance of separate data analysis according to clinical entity. The high proportion of meningitis among incident IPD in children aged under 16 years in Germany $(26 \%(628 / 2,394)$ for $2007-12)$ was similar to the proportion in Denmark (20\%) [18], but much higher than the proportion in the United Kingdom (6\%) [19]. For countries with high blood culturing rates, and therefore a high proportion of non-meningitis IPD, aggregate estimates of PCV impact on IPD may mask a differential effect on meningitis IPD. Meningitis IPD, however, has a higher clinical relevance and public health impact because case fatality and sequelae rates are about fourfold higher than for non-meningitis IPD [6].

Separate analysis (and publication) of meningitis and non-meningitis IPD cases is also useful for comparison of international data, since meningitis IPD incidence is less likely to be affected by ascertainment bias. This is demonstrated by similar incidence rates in different countries [20], while non-meningitis IPD incidence is dependent on blood culturing practices for children with fever - practices that differ between countries and can change over time [21].

Another strength of our data is the use of two independent data sources, which allows us to correct for underreporting by CRC.

A potential limitation is the comparison of two one-year periods (2009 and 2012, three years after the introduction of $\mathrm{PCV}_{7}$ and $\mathrm{PCV}_{13}$, respectively). We chose these time periods to include two cohorts of children under two years-old, who could have been fully vaccinated with either $\mathrm{PCV}_{7}$ or $\mathrm{PCV}_{13}$. To reduce random variability due to small numbers when comparing two one-year periods only, we also compared 2008-09 with 201112. This yielded almost identical results, rendering chance a less likely explanation of our findings.

A limitiation of our data is the confinement of our analysis to children aged under 16 years.

It might also be argued that the strength of the effect of higher-valent pneumococcal vaccines might be underestimated as $\mathrm{PCV}_{10}$ was already introduced in Germany in April 2009 and PCV13 in December 2009. Both higher-valent vaccines were used, when $\mathrm{PCV}_{7}$ was still on the market. The market shares of the highervalent vaccines in 2009, however, were small (PCV10: 21\%; PCV13: $7 \%$ ) and $\mathrm{PCV}_{7}$ was the predominantly used vaccine during 2009.

An overestimation of the impact of $\mathrm{PCV}_{13}$ is possible as well because of a potential increase in IPD incidence due to the influenza $A\left(\mathrm{H}_{1} \mathrm{~N}_{1}\right)$ pdmog pandemic in 2009, which had reached its peak during calendar weeks 45-48 of 2009 [2,22,23]. Again, our two-year period comparison (2008-09 vs 2011-12) did not suggest bias due to picking 2009 as the base year for comparisons.

In a commentary, Katharine O’Brian described pneumococcal disease impact evaluations as a 'messy affair' and called for 'epidemiologic rigor' [24]. The heterogeneous findings in our study, once again, point to the importance of sustained surveillance of IPD and the need for thorough and detailed analysis disentangling the vaccine impact on different clinical entities.

\section{Acknowledgements}

We would like to thank Beate Heinrich from the ESPED office for her diligent role in collecting monthly reports from hospitals and checking IPD report sheets for completeness and conclusiveness. We also thank all doctors in hospitals in Germany providing IPD case reports and laboratories contributing cases to PneumoWeb. Without their voluntary contribution, this study would not have been possible.

Parts of this work result from the Ph.D. thesis of S.W. at the medical faculty of the Ludwig-Maximilians-University of Munich (in preparation). 


\section{Conflict of interest}

The hospital surveillance system was supported by a grant from Pfizer Pharma GmbH. The sponsor had the opportunity to give comments but had no role in the data analysis and content of the manuscript.

\section{Authors' contributions}

Data administration (ESPED), data analysis, interpretation of data, drafting of the manuscript: Susanne Weiss.

Data administration (PneumoWeb), interpretation of data, drafting of the manuscript: Gerhard Falkenhorst. Interpretation of data, drafting manuscript: Rüdiger von Kries.

Drafting manuscript and serotyping: Mark van der Linden; Matthias Imöhl.

\section{References}

1. Robert Koch Institute (RKI). Empfehlungen der Ständigen Impfkommission (STIKO) am Robert Koch-Institut: Begründungen zur allgemeinen Empfehlung der Impfungen gegen Pneumokokken und Meningokokken im Säuglings- und Kindesalter. [Recommendations of the Standing Committee on Vaccination (STIKO) at the Robert Koch Institute: Scientific justification for the universal recommendation to vaccinate against pneumoccal and meningococcal disease during infancy and childhood]. Epidemiologisches Bulletin. 2006;31:2556o. Berlin: RKI; 2006. German. Available from: https:// www.rki.de/DE/Content/Infekt/EpidBull/Archiv/2006/ Ausgabenlinks/31_06.pdf? blob=publicationFile

2. van der Linden $M$, Weiß S, Falkenhorst G, Siedler A, Imöhl M, von Kries R. Four years of universal pneumococcal conjugate infant vaccination in Germany: impact on incidence of invasive pneumococcal disease and serotype distribution in children. Vaccine. 2012;30(40):5880-5. http://dx.doi.org/10.1016/j. vaccine.2012.06.068 PMID:22771186

3. Feikin DR, Kagucia EW, Loo JD, Link-Gelles R, Puhan MA, Cherian T, et al. Serotype-specific changes in invasive pneumococcal disease after pneumococcal conjugate vaccine introduction: a pooled analysis of multiple surveillance sites. PLoS Med. 2013;10(9):e1001517.http://dx.doi.org/10.1371/ journal.pmed.1001517 PMID:24086113

4. Miller E, Andrews NJ, Waight PA, Slack MP, George RC. Effectiveness of the new serotypes in the 13-valent pneumococcal conjugate vaccine. Vaccine. 2011;29(49):912731.http://dx.doi.org/10.1016/j.vaccine.2011.09.112 PMID:21983361

5. Göbel U, Heinrich B, Krauth KA, Steingrüber HJ, von Kries $R$. [Process and outcome quality of the German Paediatric Surveillance Unit (ESPED)]. Klin Padiatr. 2010;222(2):92-7. German. PMID:20146163

6. von Kries R, Siedler A, Schmitt HJ, Reinert RR. Proportion of invasive pneumococcal infections in German children preventable by pneumococcal conjugate vaccines. Clin Infect Dis. 2000;31(2):482-7.http://dx.doi.org/10.1086/313984 PMID:10987709

7. Rückinger $S$, van der Linden $M$, Reinert RR, von Kries R, Burckhardt F, Siedler A. Reduction in the incidence of invasive pneumococcal disease after general vaccination with 7-valent pneumococcal conjugate vaccine in Germany. Vaccine. 2009;27(31):4136-41.http://dx.doi.org/10.1016/j. vaccine.2009.04.057 PMID:19406190

8. Rückinger S, von Kries R, Reinert RR, van der Linden M, Siedler A. Childhood invasive pneumococcal disease in Germany between 1997 and 2003: variability in incidence and serotype distribution in absence of general pneumococcal conjugate vaccination. Vaccine. 2008;26(32):3984-6.http://dx.doi. org/10.1016/j.vaccine.2008.04.031 PMID:18495301

9. LaPorte RE, McCarty DJ, Tull ES, Tajima N. Counting birds, bees, and NCDs. Lancet. 1992;339(8791):494-5.http://dx.doi. org/10.1016/0140-6736(92)91103-F PMID:1346847

10. Chapman DG. Some properties of the hypergeometric distribution with applications to zoological sample censuses. Berkeley, CA: University of California Press; 1951.

11. Rückinger $S$, van der Linden $M$, Reinert RR, von Kries $R$. Efficacy of 7-valent pneumococcal conjugate vaccination in Germany: An analysis using the indirect cohort method. Vaccine. 2010;28(31):5012-6. PMID:20546832
12. Statistisches Bundesamt. [Federal Statistical Office of Germany]. Tabelle B15. A1 Bevölkerung nach Alters- und Geburtsjahren 2000-2012. [Table B15, A1 Population according to age and birth year 2001-2012]. Wiesbaden: Federal Statistical Office of Germany; 2013. Obtained by email from the Federal Statistical Office in Germany (fortschreibung@ destatis.de). German.

13. Armitage P, Berry G. Statistical methods in medical research. 3rd ed. London: Blackwell; 1994.

14. Song JY, Nahm MH, Moseley MA. Clinical implications of pneumococcal serotypes: invasive disease potential, clinical presentations, and antibiotic resistance. J Korean Med Sci. 2013;28(1):4-15.http://dx.doi.org/10.3346/jkms.2013.28.1.4 PMID:23341706

15. Molander V, Elisson C, Balaji V, Backhaus E, John J, Vargheese $R$, et al. Invasive pneumococcal infections in Vellore, India: clinical characteristics and distribution of serotypes. BMC Infect Dis. 2013;13(1):532.http://dx.doi.org/10.1186/1471-233413-532 PMID:24206667

16. Kaplan SL, Barson WJ, Lin PL, Romero JR, Bradley JS, Tan TQ, et al. Early trends for invasive pneumococcal infections in children after the introduction of the 13-valent pneumococcal conjugate vaccine. Pediatr Infect Dis J. 2013;32(3):203-7.http:// dx.doi.org/10.1097/INF.ob013e318275614b PMID:23558320

17. Statens Serum Institut (SSI). Invasive pneumococcal disease and PCV coverage 2012. EPI-NEWS, No 19, 2013. Copenhagen: SSI; 8 May 2013. Available from: http://www.ssi.dk/English/ NewS/EPI-NEWS/2013/No\%2019\%20-\%202013.aspx

18. Harboe ZB, Valentiner-Branth P, Benfield TL, Christensen JJ, Andersen PH, Howitz M, et al. Early effectiveness of heptavalent conjugate pneumococcal vaccination on invasive pneumococcal disease after the introduction in the Danish Childhood Immunization Programme. Vaccine. 2010;28(14):2642-7.http://dx.doi.org/10.1016/j. vaccine.2010.01.017 PMID:20096392

19. Miller E, Andrews NJ, Waight PA, Slack MP, George RC. Herd immunity and serotype replacement 4 years after seven-valent pneumococcal conjugate vaccination in England and Wales: an observational cohort study. Lancet Infect Dis. 2011;11(10):7608.http://dx.doi.org/10.1016/S1473-3099(11)70090-1 PMID:21621466

20. Jefferson T, Ferroni E, Curtale F, Giorgi Rossi P, Borgia P. Streptococcus pneumoniae in western Europe: serotype distribution and incidence in children less than 2 years old. Lancet Infect Dis. 2006;6(7):405-10.http://dx.doi.org/10.1016/ S1473-3099(06)70520-5 PMID:16790381

21. Rüggeberg JU, Ketteler K, MacKenzie CR, Von Kries R, Reinert $\mathrm{RR}$, Schroten H. Blood culture sampling rates at a German pediatric university hospital and incidence of invasive pneumococcal disease. Infection. 2004;32(2):78-81.http:// dx.doi.org/10.1007/s15010-004-3104-2 PMID:15057571

22. von Kries $R$, Weiss $S$, Falkenhorst $G$, Wirth $S$, Kaiser $P$, Huppertz HI, et al. Post-pandemic seroprevalence of pandemic influenza $A\left(\mathrm{H}_{1} \mathrm{~N}_{1}\right) 2009$ infection (swine flu) among children «18 years in Germany. PLoS One. 2011;6(9):e23955.http:// dx.doi.org/10.1371/journal.pone.0023955 PMID:21915270

23. Robert Koch Institute (RKI). Bericht zur Epidemiologie der Influenza in Deutschland, Saison 2009/10. [Report on the epidemiology of influenza in Germany, season 2009/10]. Berlin: RKI; 2010. German. Available from: http://influenza.rki. de/Saisonberichte/2009.pdf

24. O'Brien KL. PCV13 impact evaluations: the obvious and the unpredicted. Pediatr Infect Dis J. 2013;32(3):264-5.http:// dx.doi.org/10.1097/INF.obo13e3182787f89 PMID:23558322 